\title{
The Importance of Teacher's Effectiveness
}

\author{
Elizabeth Block, Fran Crochet, Leslie Jones, Tiffany Papa \\ College of Education, Nicholls State University, Thibodaux, United States \\ Email: Leslie.jones@nicholls.edu
}

Received August 31 ${ }^{\text {st }}$ 2012; revised September 30 ${ }^{\text {th }}$, 2012; accepted October $16^{\text {th }}, 2012$

\begin{abstract}
Heightened emphases are on teachers and effective teaching particularly linked to the performances of students in K-12 schools. The purpose of this article is to review perspectives of teaching over a period of several decades in the literature and to investigate the perceptions of practicing teachers enrolled in graduate school regarding necessary components of effective teaching. Results indicate that many of the notions indicated in the literature as essential for effective teaching are aligned with the perceptions of educators currently enrolled in graduate school. There are definite implications embedded in the article for school leadership.
\end{abstract}

Keywords: Teacher Effectiveness; Accountability; Teaching Methods

\section{Introduction}

The performance of American students and teacher accountability are highlighted in many of the recent and older publications. In Fullan's (2010) book, All Systems Go, Sengne (2010) cites the rapid decline in achievement of our students. Segne (2010) observes that fifty years ago, our nation's students ranked at the top of the world in education while our current ranking among advanced countries is at the bottom. The graduation rates at our schools reflect the under-performance of our students.

Fullan (2010) states that there are high performing schools throughout the country, and at least ten years earlier, Slavin \& Fashoa (1998) noted that there were positive changes in student learning in schools. Murphy \& Adams (1998) also noted in the same era that many of the educational reform efforts have not lived up to expectations (1998). In addition, Segne documents that we have allocated money to ineffective reform efforts and real change is still possible.

According to Segne and colleagues (1999,) the pre-requisite for school reform is that we must believe change is possible. Fullan (2010) states that the importance of conviction is critical for change. The conviction should be coupled with a clear framework and practical tools. Odden's (1992) perspective of reform is aligned with the perspectives of Segne (1999) and Fullan (2010). He says it takes will and persistence. Kennedy (2003), Segne (2010), and Schmoker (2011) also provide explanations for the lack of success in reform.

Kennedy (2003) suggests that school reform has not lived up to expectations for the following reasons: changes must be systemic; changes must be guided by a shared vision with measurable goals and benchmarks; change must involve all key stakeholders; change must be planned and incremental; change must address the needs and responsibilities of all stakeholders; and change should be a continuous, evolving process guided by empirical data. In Raising Test Scores for All Students, Kennedy (2003) asserts that the nature of much reform has been too fragmented.

Kennedy emphasized the need for positive changes in schools through careful data analyses linked to needs assess- ments with a focus on promoting positivism in climates of schools. In a recent publication, Schmoker (2011) states that "time" is one of the critical elements for change. This is also noted in Senge and Colleagues' (1999) The Dance of Change. Schmoker (2011) notes that it takes as many as seven years to effect positive change in schools. Educators should focus on "what is essential" and "ignore the rest."

Obviously, the issues of student performance, under-performance, and reform are matters that are discussed by many researchers. Furthermore, there are other researchers who address the legislation and implications linked to accountability and reform. The most recent accountability legislation includes A Nation at Risk and No Child Left Behind (with its reauthorization). Currently, state boards of education are applying for waivers to be exempt from many of the mandates of the reauthorization of No Child Left Behind.

The increased awareness and attention on student performances, accountability, and reform have also led to greater discourse among researchers and educators regarding the roles of teachers and principals. Todd Whitaker (2004) says that an effective teacher is an effective leader, and an effective leader is a great teacher or other student growth indicators. That is, teachers who are great have great leadership skills. Leaders who are great are effective teachers.

In Louisiana, reform and accountability for teachers and principals have recently been linked with the passage of Act 54 . Fifty percent of teacher evaluations are based on the learning of students measured by the value added model or other student growth measures. In this article, we focus on the effective teacher from the perspective of teaching as a process and the means/methods to evaluate effective teaching. In this article, the competencies and characteristics of effective teaching are discussed from multiple perspectives-as the perspectives evolved historically-Langlios \& Zales (1991), Cashmere (1999), Sanders (2000), and Olivia \& Pawlas (2008).

In addition to providing an historical perspective of effective teaching from the literature, the authors surveyed teachers in a graduate class regarding their perspectives of effective teaching. A focus group was also conducted with the graduate class 
which will be discussed in this article. Several states have recently adopted the common core as the curriculum for English Language Arts and mathematics. The instrument for teacher evaluation (which is the indicator of teacher effectiveness) will ultimately be adjusted in many districts and states. In Table 1, the four perspectives of effective teaching which are discussed are summarized.

\section{Langlois and Zales’ Perspective}

Langlois and Zales (1991) provide a perspective of effective teaching that includes a profile which may not identify every effective teacher, but it describes a basis to start. The profile outlines four categories-time for learning, importance of routines, teacher to student, and praise and accountability. Time for learning focuses on effective teacher behaviors associated with time factors while implementing instruction. Langlois and Zales (1991) suggest that effective teachers engage students in activities and make the most of instructional time.

Students should be engaged in learning for the maximum amount of time with the least amount of interruptions as possible. Engaging students in the learning process does require the use of the competencies suggested by Olivia and Pawles (2008). The competency of following a model of instruction is critical because teachers must plan the activities to engage students and then implement the strategies. The time for learning profile suggests that teachers hold high expectations for students and manage student behaviors. Both of these teacher behaviors/dispositions have been discussed considerably among educators; the authors believe that there is agreement that both are necessary in classroom environments for teaching to occur.

The second category in the profile described by Langlois and Zales (1991) is the importance of routines. It is suggested that effective teachers are organized and use a sequence of activities; however, a variety of teaching methods and materials are used so that students do not become bored. Classrooms where teachers exhibit these behaviors are structured learning climates where students feel the freedom to take care of their responsibilities. In addition, continuity and consistency are practices that underscore student learning.

Teacher to student is the third category of the profile which focuses on the communication skills and the ability of the teacher to use information on students in planning and implementing the lesson. Effective teachers are good communicators, and they treat students with respect. According to Bagin and Gallagher (2001), educators have a false impression regarding the ability to communicate. It is critical for teachers to have positive interaction with students. It enhances the possibility of effective student achievement.

In lesson planning and implementation, effective teachers use the knowledge of their students' interests as a motivational tool to help meet the needs of their students. Students feel comfortable and willing to be engaged when the atmosphere is positive and respectful. Cashmere (1999) also discusses the importance of engaging students as a necessary component of effective teaching. As previously stated, the engaging of students in learning requires teachers to use the model of instruction that Olivia and Pawles (2001) outline as being critical to effective teaching. Students tend to retain information longer when they are actively involved in their learning.

The fourth category of the profile is praise and accountability. Praising students is one of the ways to give feedback to stu- dents. Olivia and Pawlas (2008) also noted the importance of providing students with feedback as a means of being skilled in the systematic approach as opposed to older approaches. Teachers who provide feedback to students are teachers who informally and formally assess students.

The informal assessment of students is often ignored or omitted by teachers, but it must occur continuously throughout the lesson. Conscious efforts must be made by teachers to give praise and constructive feedback-effective teachers plan to informally assess students as the lesson is being implemented. Constructive feedback is explicit and specific and provides explanations to students regarding performance. Accountability must also be ensured by teachers. The methods by which teachers ensure accountability include establishing routines, planning, and extending the subject to other disciplines.

\section{Cashmere's Perspective}

Cashmere (1999) views effective teaching as an art and a science. This perspective of effective teaching also suggests that there are competencies that effective teachers possess. In addition, Cashmere suggests that there are behaviors/dispositions exhibited by effective teachers. According to Cashmere (1999), the science and art must be cleverly combined.

Teachers use pedagogy (the science)-their knowledge of teaching methodology and content to craft (the art) lessons that engage students; the lessons are translated with the use of artistic skills. The use of the science implies that teachers must have knowledge and skills. The knowledge base that effective teachers possess is two-fold. An effective teacher has content knowledge of their specific subjects and knowledge of methodology-pedagogy which is the how to present the lesson. Teachers should have at their disposal multiple ways to present lessons and the ability to adapt/ adjust instruction.

The ability to adapt/adjust instruction requires the use of the teachers' artistic skills. If students are not comprehending, effective teachers recognize this and teachers begin to use different presentation styles, activities, or examples. Creativity and flexibility becomes necessary in making adjustments which require the teacher to use skills and exhibit behaviors of engaging in competent practices and serving students. Therefore, the knowledge, skills, and dispositions of teachers are important in the effective delivery of instruction. These concepts are also embedded in the six competencies of Olivia and Pawlas (2008). In Table 1, the competencies of Cashmere (1991) and Olivia and Pawlass are presented along with two other persepctives.

\section{Sanders' Perspective}

In his writing, Characteristics of Effective Teaching, Sanders (2000) uses the work of Harry Murray to provide twelve distinctive characteristics of effective teachers. The characteristics are:

- Enthusiasm;

- Clarity;

- Interaction;

- Organization;

- Pacing;

- Disclosure;

- Speech;

- Rapport;

- Relevance; 
- Learning centered;

- Flexibility; and

- Leadership.

Several of these characteristics are addressed in the perspectives of Olivia and Pawlas (2008), Cashmere (1999), and Langlois and Zales (1991). Furthermore, several of these characteristics must be exemplified by effective teachers to use perspectives suggested by the other theorists. For instance, both Langlois and Zales (1991) and Olivia and Pawles (2008) suggest that effective teachers engage students. Teachers cannot be effective at engaging students unless they possess some enthusiasm-making an effort to solicit student attention. In addition, to effectively engage students, teachers must be flexible-open to change. There must be interaction-ways to foster participation among students; it is also essential for the teacher to be organized and learning centered to engage students.

Sanders (2000) gives descriptors of the twelve characteristics. In addition to soliciting student attention and interest, a teacher who is enthusiastic speaks in a dramatic way, moves while presenting, gestures with hands, maintains eye contact, and smiles while teaching. An effective teacher is able to clarify concepts (clarity). In addition, a teacher who exhibits clarity gives several examples, uses concrete everyday examples, defines new terms, repeats directions, and points out practical applications. Effective teachers foster student participation (interaction). Teachers who are effective at developing interaction (encouraging questions from students), avoid direct criticism, praise students, ask questions to the whole class and individual students, and use a variety of media activities.

Teachers who are effective at organization use headings and subheadings to organize presentation, use outlines, clearly indicate transitions from one topic to the next, give preliminary overviews, and give explanations of how topics fit subject areas. Pacing is the fifth characteristic cited by Sanders (2000) as a characteristic of effective teachers. Teachers who are effective at pacing are teachers that digress rarely, cover the important material, ask and confirm if students understand prior to proceeding, and stick to the point when answering questions from students. Disclosure implies explicitness regarding course requirements. Teachers who exhibit disclosure advise students, provide sample exam questions, tell students expectations, state objectives, remind students of deadlines, and review objectives of the entire course.

According to Sanders (2000), effective teachers engage in voice relevancy. They speak at appropriate volumes; they speak clearly; and they speak at an appropriate pace. The eighth characteristic of an effective teacher, as suggested by Sanders (2000), is rapport. Effective teachers who have rapport with students address individual students by name, announce availability for consultation, offer help to students with problems, show tolerance, talk with students, and acknowledge diversity.

Bridging the gap between course content and the "real" world is important for student understanding and is the next identified characteristic. Students need to see the relevancy of information. Teachers who demonstrate the need to use relevancy in instruction provide holistic context for learning, integrate materials from the world, provide access to external sources, and provide opportunities for learners to apply learning to the external world.

The tenth characteristic identified by Sanders (2000) is learner centered. Teachers who are learner centered focus on the learning outcomes and growth of students; they are design- ers and coaches; they work in teams when necessary; and they have some control over the learning process. Flexibility follows and implies openness to change and diverse ways of looking at material. Effective teachers are flexible, and they appeal to different learning styles and appreciate multiple perspectives. The final characteristic is leadership. Teachers who are leaders model civil behavior, model intellectual engagement, and provide intellectual challenges for all levels of learner abilities.

\section{Olivia and Pawlas' Perspective}

Olivia and Pawlas (2008) suggest that there are six competencies teachers should possess in order to be effective. Teachers should be skilled in:

- following a systematic approach;

- following a model of instruction;

- writing instructional goals and objectives;

- applying taxonomies of instructional objectives;

- describing and analyzing learning tasks; and

- organizing instructional plans.

When teachers utilize a systematic approach for instructional design, the focus for instruction is on what the learner will do (objectives). The daily use of performance written objectives can enhance student performance on standardized tests. Older approaches focused on what the teacher presently does which takes the concentration away from students. Engaging students in learning becomes critical in maintaining the attention of learners. Using the systematic approach, the objectives are apparent to students before instruction begins; continuous feedback is provided, and the necessary redesign of activities is provided.

There are many advantages for students when feedback is provided. Giving students feedback may serve as "eye-openers" for students regarding their present level of functioning, and feedback may be used to motivate students. In addition, some students need constant reinforcement that feedback provides. Redesigning instruction as it is being presented is important because it may be necessary for the teacher to change a presentation style or change some component of the lesson for students to grasp the concepts from the lesson. Feedback and redesign are not embedded in the older approaches. Obviously, the systematic approach produces the most effective teaching because it is the most student-centered approach.

Olivia and Pawles' (2008) second competency for teachers involves planning, presenting, and evaluating instruction. Within this model, there are multidimensional considerations of each component. Classroom management is embedded in planning, presenting, and evaluating instruction. Planning precedes presentation and evaluation of instruction, and it is essential for the effective delivery of instruction; it requires teachers to analyze learner needs in order to determine appropriate goals and objectives, which is the third skill suggested by Olivia and Pawles (2008). Determining goals and objectives are embedded in the second competency.

The analyses of learner needs dictate that teachers should possess a sense of familiarity with the learners which may demand that teachers do research on individual students-researching records, cumulative folders, and test scores to determine their students' individual strengths and weaknesses. Consequently, planning and writing instructional goals and objectives based on the analysis data will truly benefit all involved including the "whole child." The research on students is also necessary in the 
application of taxonomies - the fourth competency. When appropriate, behavioral objectives should be written for the cognitive, affective, and psychomotor domains. Although the arts and physical activity are sometimes minimized in schools, it is the responsibility of schools to develop the "total child." Most of the objectives written by content teachers who are not physical education teachers are cognitive behavior objectives; however, it is necessary for teachers to write objectives that focus on the affective and psychomotor domain.

In the article, "Enhancing Your Teacher Effectiveness," the author suggests that students should be involved in planning. Students must be involved in identifying their learning needs and outcomes. The involvement from students helps to ensure that goals and objectives are attainable and realistic for students. As teachers plan and decide on appropriate goals and objectives, teachers must also decide on implementation strategies. The student involvement should continue as teachers determine strategies to implement. The use of the fifth competency is important as strategies are determined. Specific learning tasks should be aligned with each learning objective, and the strategy must compliment the learning tasks. The strategies utilized must also be right for the learner, the subject matter, the time available, the resources available, the facilities, the objective, and the teacher. Alignment of objectives with strategies, activities, and learning tasks is critical for effective teaching.

At some point, after the teacher has worked at developing the previously discussed competencies, the teacher must put all of the components together. The organization of lesson plans begins with the teacher looking at the content knowledge and the outcomes. The content must also be divided into topics which required the teacher to estimate the amount of time each topic will take for student mastery. Implementation of the material then becomes critical. Each lesson should have a beginning, middle, and end. The teacher implements the plan-at each stage of the lesson; effective teachers make the necessary adjustments based on learner needs. Olivia and Pawles (2008) suggest that teachers must inform students what they are going to tell them, tell them, and then tell them what you have told them.

As previously discussed throughout the article, there are some obvious areas of overlap on effective teaching as viewed from the four perspectives. The perspectives are presented in Table 1. However, there are many variations in the perspectives. Furthermore, many other perspectives exist. Regardless of the perspective embraced regarding effective teaching, the concept is very complex and difficult to define and/or describe.

The most important view of effective teaching is its role as a component of accountability. The effective teaching and schools research suggest that effective teaching makes a difference in student achievement (Olivia \& Pawlas, 2008). Over twenty years ago, A Nation at Risk cited the need for improvement for our nation's schools. The recent NCLB legislation reemphasizes the need for improvement. A critical place to begin is with a critical look at teaching-classroom teachers must embrace effective teaching practices.

Teacher effectiveness is one of the ultimate goals of education. The way in which we measure teacher effectiveness is through a teacher evaluation tool. "Teacher evaluation has emerged as a key strategy for improving student outcomes in public education” (Curtis \& Wiener, 2012: p. 3). Teachers vary in their effectiveness and subsequently, evaluation instruments need to identify and address these differences. Over the last couple of years, most states have developed new policies re- garding teacher evaluations, including requirements to factor student achievement (test scores) into individual teacher evaluations. The field is moving quickly in this direction and is now implementing these new evaluations (Curtis \& Wiener, 2012).

In order for teacher effectiveness to impact educational improvement, teacher evaluations must be completed correctly. Historically, public education has tried methods of evaluating teacher effectiveness that have fallen short due to poor planning and weak execution (Curtis \& Wiener, 2012).

Most of the current teacher evaluations focus on giving the teacher a rating and holding that teacher accountable for his/her performance. Teachers are categorized as high performers or low performers. The high performers are recognized as such and the low performers are pursued for dismissal. This focus is problematic in that the evaluation tool usually does not include support for teacher improvement. The majority of teachers fall in middle range of performance evaluations, therefore, leading schools to mediocre teaching instead of excellence in education (Curtis \& Wiener, 2012).

To reach the goal of teacher effectiveness and ultimately student success, teachers must be evaluated. The evaluating instruments must be further studied in order to maximize the potential of teacher evaluations. Additionally, instruments need to identify each teacher's capabilities and insure a rating on the "whole" teacher and not just test scores. This may retain more effective teachers for longer periods of time (Curtis \& Wiener, 2012).

In Zapeda's (2007) Instructional Tools, she discusses the importance of classroom observations for improving the professional development opportunities for teachers. School leaders who evaluate teachers can use the evaluating instruments as a basis for beginning discussions that lead to both informal and more formal professional development opportunities for teachers. Professional development should obviously lead to improvements in teaching and other professional dispositions.

\section{Method for Focus Group and Surveying}

A focus group was conducted with eleven graduate candidates enrolled in the K-12 School Leadership Program at Nicholls State University. These candidates were also surveyed. The K-12 School Leadership Program is a two-year cohort model where candidates matriculate through courses-taking all courses in the same semesters. The focus of the curriculum is the Interstate School Licensure Consortium Standards.

Candidates participating in the focus groups and completing the surveys are candidates completing the program. They are enrolled in the Internship; the final field-experience of the program. Eight of the eleven candidates have five or more years of teaching experiences in education; which represents more than 70 percent of the participants in the study.

Two of the authors facilitated the focus group. One of the authors has facilitated several of the courses with the candidates over two years; and the other facilitator has interacted with several of the candidates through other university-based experiences. The candidates participating in the focus group were also surveyed.

The questions/statements in the survey were designed by all of the professors involved in the project. The basis for the survey centered around the research perspectives on effective teaching along with perspectives of teacher evaluations embedded in the new value-added model and the compass instru- 
ment. The surveys were also reviewed by additional faculty members for purposes of reliability.

The perspectives of effective teaching are discussed in the article; the included perspectives are Langlios \& Zales (1991), Cashmere (1999), Sanders (2000), and Olivia \& Pawlas (2008). Value-added is the teacher evaluation tool based on a growth model for students' performances that has a heightened focus in the area; and the compass instrument is being piloted in Louisiana as a teacher observation instrument.

The survey was administered prior to the focus group discussions in an effort to eliminate any biased opinion projected on the surveys. That is, the authors attempted to eliminate the potential of the surveys impacting the responses in the focus group. The following questions were asked in the focus group:

Question from the Literature Review

What attributes would you consider a highly effective teacher to possess?

Questions from Value-added

1) Do you agree that the measurements of teacher growth instead of focusing on other variables are a fairer way of evaluating teachers?

2) Do you believe that prior achievement should be the primary indicator of future success?

3) Do you think prior achievement is the most important factor in predicting achievement?

Questions from the Teacher Rating Forms-Compass

Do you believe a portfolio will be necessary to document:

a) Environment Standard 3 (creates opportunities for students, families, and others to support accomplishment of learning goals)

b) Professionalism Standard 1 (teacher engages in self-reflection and growth opportunities to support high levels of learning for all students)

c) Professionalism Standard 2 (teacher collaborates and communicates effectively with families, colleagues, and the community to promote students' academic achievement and to accomplish school's mission)

Anecdotal notes were written as the focus group was conducted; and the focus group was video-recorded as a means to add validity to the anecdotal records. Also, member-checking of the notes occurred for purposes of reliability.

Interestingly, candidates participating in the data gathering processes of both surveys and focus group noted that the perspectives of effective teaching cited in the literature are important attributes of effective teaching. When asked in the focused groups, what are the characteristics of highly effective teachers, the following responses were given:

- Goes beyond the five part lesson of aligning objectives with outcomes;

- Is student-centered; learner-centered;

- Has high performing students;

- Demonstrates student growth;

- Fulfills criteria for growth;

- Engages students in rigor and relevance;

- Differentiates instruction according to needs of students;

- Engages students;

- Uses interventions;

- Is self-reflective;

- Has ownership in the classroom;

- Has great content knowledge;

- Has knowledge of students;

- Is Flexible;

- Is enthusiastic;
- Is excited; and

- Is the whole package (reflects; engages; sets expectations; have positive climates; knows students).

The responses were categorized and coded. The emerging themes from the categorizations are: student centered and student descriptors; knowledge and skills; and disposition-based responses. That is, the responses of the focus group participants indicate that effective teachers are student centered; possess specific knowledge and skills; and exhibit specific dispositions.

The responses that are coded as student-centered/student descriptors are:

Is student-centered; learner-centered;

Has high performing students;

Demonstrates student growth;

Engages students in rigor and relevance;

Differentiates instruction according to needs of students;

Engages students.

The responses that are categorized and coded as knowledge and skills are:

Fulfills criteria for growth;

Is self-reflective; and

Has great content knowledge.

The responses that are coded dispositions based are:

Has ownership in classroom;

Is flexible;

Is excited;

Is Whole Package (reflects; engages; sets expectations; have positive climates; knows students).

Two miscellaneous items were not categorized:

Goes beyond the five part lesson of aligning objectives with outcomes.

Table 2 (at the conclusion of the paper) includes a chart that depicts the findings from the survey; One hundred percent of the candidates reported that the characteristics of effective teaching from the literature are "highly effective" or "effective" teaching competencies.

Questions/statements on the survey 9 - 33 reflect the perspectives of effective teaching cited in the literature. Questions/ statements 2 - 8 are components aligned with value-added and the compass. For this area, there was variability in the statements expressing agreement and disagreement from the participants. The majority of the graduate candidates either "strongly agreed" or "agreed" that the performance of teachers should be linked to prior achievement and growth of students. In addition, the majority also "agreed" or strongly agreed that portfolios be used to document components for teacher evaluations.

See Table 2 for all of the responses.

\section{Future Implications}

It is evident from the survey and focus group that the qualities and competencies required of effective teachers, as expressed in the literature over the past two decades, is still culturally relevant in today's classrooms and schools. In addition, the proposed means by which effective teachers are evaluated (value-added, the compass, and portfolios) are also deemed to be important and accurate means by which teachers should be assessed. Given the political and social discourse over the topic of teacher evaluation in states such as Louisiana, it is often difficult to ascertain which measure will be most effective in improving the overall quality of education at the state and national levels. 
Table 1.

A look at four perspectives.

\begin{tabular}{cccc}
\hline Langlios \& Zales (1991) & Cashmere (1999) & Sanders (2000) & Olivia \& Pawlass (2008) \\
\hline Four Categories & Competencies \& Dispositions & 12 Characteristics & 6 Competencies Skilled in Following \\
Time for Learning & Art \& Science & Enthusiasm & Model of Instruction \\
Routines & Science-Pedagogy & Clarity & Writing Instructional Objectives \\
Teacher to Student & Art-Engage Students & Interaction & Applying Taxonomies of Instructional Objectives \\
Praise \& Accountability & Organization & Describing and Analyzing Learning Tasks \\
& Pacing & Organizing Instructional Plan \\
& Disclosure & \\
& Speech & \\
& Rapport & \\
& Relevance & \\
& Learning centered & \\
& Flexibility & \\
& Leadership & \\
& & \\
& &
\end{tabular}

The sample utilized for this research includes teachers who are seeking further professional development in the form of an advanced degree. This sample was diverse in terms of age, sex, race, schools of employment and school performance or ratings. The fact that the majority of these candidates feel that the performance of teachers should be linked to prior achievement and growth of students is significant in that these are motivated individuals who have advanced their own knowledge and skills through graduate school. Rather than complacently biding their time in classrooms, these individuals feel it is incumbent upon the teacher to elevate his/her professional status through an advanced degree.

While the sample in the study was diverse in its composition, a larger sample from a broader geographic region would allow for greater generalizability. In addition, this sample included individuals who personally sought out professional growth through higher education. It would be beneficial to survey teachers who are just starting their careers and those who are not seeking a master's degree to determine different perspectives from individuals who do not possess the same motivation or initiative with regard to professional development. In addition, it would be beneficial to include teacher participants who have been evaluated via the current efficacy instrument so that their perspectives could be aligned with their scores.

The findings from this study have implications on the future of teacher evaluation in Louisiana and the nation at large. Presently, the tools and methods used to evaluate teacher efficacy change almost daily. Lawmakers and boards of education should be guided by the perspectives of Langlios \& Zales (1991), Cashmere (1999), Sanders (2000), and Olivia \& Pawlas (2008) in creating or adopting an instrument that is comprehensive in measuring the attributes of teacher efficacy as outlined by these authors. Some states are adopting measures that place too much weight on one area (student achievement, teacher dispositions, or teacher knowledge) whereas a more balanced approach helps to identify areas of real weakness or mediocrity and a plan for growth.

\section{Conclusion}

There are obviously varying perspectives of effective teaching in the literature. Perspectives of effective teaching are presented in this article from an historical vantage point. The perspectives of Langlios \& Zales (1991), Cashmere (1999), Sanders (2000), and Olivia \& Pawlas (2008) are discussed with Langlios \& Zales' categories linked to a profile of effective teaching.

The perspective of Cashmere suggests that effective teaching is an art and a science in which the art and science must be cleverly combined. Twelve distinct characteristics necessary for effective teachers are identified by Sanders, some of which are knowledge-based while others are disposition-based. Olivia \& Pawlas (2008) identified six competencies in which teachers should be skilled.

The historical literature review and the current emphases on teaching aligned with accountability are the guiding framework used to develop a survey along with questions for a focus group. Graduate candidates were surveyed, and a focus group was also conducted with the candidates surveyed. One hundred percent of the candidates surveyed suggested that the indicators in the literature of effective teaching are critical attributes of effective teaching. In other words, the candidates agreed that all of the categories and characteristics identified in the literature are critical for effective teaching. Further study is needed on the degree that the competencies are integrated into instruction.

All of the candidates agreed that measurement of growth instead of achievement was fairer in evaluating teacher performance and was the primary indicator of future success. The majority of candidates also believed that portfolios would be necessary in documenting performances for evaluations. The discrepancy appeared in whether prior achievement is the most 
important factor in predicting achievement and if students should rate the performances of teachers.

Furthermore, the analyses of coding and categorization from the focus group suggested that effective teachers are student centered; possess specific knowledge and skills; and exhibit specific dispositions. The analyses of the study align with Schmoker's (2011) ideals. He suggests that educators are knowledgeable of best practices. The challenge often comes with implementation of best practices and other issues.

Odden (2009: p. 22) and Collins (2005) make similar assertions regarding the implementation of best practices in schools. Odden (2009) suggests that "will and persistence" are critical to implementation of best practices for educators. He believes that failure to improve schools is not due to a lack of "know how." That is, educators are aware of the "hows" to improving schools. Collins (2005) suggests that innovation is not needed; the key to success is "simplicity and diligence."

Educators participating in the study agreed with the concepts cited historically in the literature as being essential. Table 2 has the summary of results. This in a sense validates that the knowledge of best practices is prevalent in the group surveyed. The current challenge and future challenge for implementation of best practices will be closely aligned with the roles of school leaders in promoting professional development along with informal and formal professional development by teachers and other stakeholders.

\section{REFERENCES}

Bagin, D., \& Gallagher (2001). The school and community relations. Boston, MA: Allyn and Bacon.

Cashmere, A. (1999). The art of effective teaching. URL (last checked 3 March 2011).

http://www.curry.edschool.virginia.edu/gove/edis771/springquest/

Cashmere (2011). Enhancing your teacher effectiveness. URL (last checked 3 March 2011)

http://www2.honolulu.hawaii.edu/facdev/guidebk/teachtip/m-files/m-en hanc.html

Collins, J. (2005). Good to great and the social sectors: A monograph to accompany good to great. New York: Harpercollins Publishers.

Curtis, R., \& Wiener, R. (2012). A guide to developing teacher evaluation systems that support growth and development. Washington, DC: The Apen Institute.

Fullan, M. (2010). Failure is not an option: Six principles that guide student achievement in high performing schools. Thousand Oaks, CA: Corwin Press.

Langlois, D., \& Zales, C. (1991). Anatomy of a top teacher. American School Board Journal, 178, 44-46.

Murphy, J., \& Adams, J. E. Jr. (1998). Reforming America's schools 1980-2000. Journal of Educational Administration, 36, 426-444. doi:10.1108/09578239810238438

Olivia, P., \& Pawlas G. (2001). Supervision for today's schools (6th ed.). New York: Wiley \& Sons.

Odden, A. (2009). Ten strategies for doubling student performance. Thousand Oaks, CA: Corwin Press.

Odden, A (1992). Rethinking school finance: An agenda for the 1990s. New York: Jossey Bass.

Sanders, P. (2000). Characteristics of effective teaching. URL (last checked 2009).

http://www.wmich.edu/teachlearn/teaching/chair_effect_tch.html

Senge, P., Kleiner, R., Roberts, C., Roth, G., Ross, R., \& Smith, R. (1999). The dance of change. New York: Doubleday Publishers.

Schulman, L. (1987). Knowledge and teaching: Foundation of the new reform. Harvard Educational Review, 5, 1-22.

Schmoker, M. (2011). Focus: Elevating the essentials to radically improve student learning. Alexandria, VA: ASCD.

Slavin, R. E., \& Fashola, O. S. (1998). Show me the evidence: Proven and promising programs for America's schools. Thousand Oaks, CA: Corwin Press.

Whitaker, T. (2004). Setting the tone leadership. Association of California School Administrators, 33, 20-22.

Zapeda, S. (2007). Instructional supervision: Applying tools and concepts. New York: Eye of Education. 
Table 2.

\begin{tabular}{|c|c|c|c|c|}
\hline A. Teacher less than 5 years. & $\begin{array}{l}\text { B. Teacher more } \\
\text { than } 5 \text { years. }\end{array}$ & $\begin{array}{l}\text { C. Administrator } \\
\text { less than } 5 \text { years. }\end{array}$ & $\begin{array}{l}\text { D. Administrator more } \\
\text { than } 5 \text { years. }\end{array}$ & E. Other \\
\hline 1) 1 & 8 & & & 2 \\
\hline A. Strongly agree/favor & B. Agree/Favor & C. Disagree & D. Strongly disagree & \\
\hline $\begin{array}{l}\text { 2) Measurement of Growth instead of achievements are fairer } \\
\text { ways of evaluating teachers. } \\
3\end{array}$ & 8 & & & \\
\hline $\begin{array}{l}\text { 3) Prior achievement should be the primary indicator of future } \\
\text { success. } \\
5\end{array}$ & 6 & & & \\
\hline $\begin{array}{l}\text { 4) Prior achievement is the most important factor in predicting } \\
\text { achievement. }\end{array}$ & 5 & 4 & 2 & \\
\hline $\begin{array}{l}\text { 5) Students should rate their teacher’s performance. } \\
2\end{array}$ & 5 & 3 & 1 & \\
\hline $\begin{array}{l}\text { 6) A portfolio will be necessary to document Environment } \\
\text { Standard Three of the Compass. }\end{array}$ & 10 & 1 & & \\
\hline $\begin{array}{l}\text { 7) A portfolio will be necessary to document Professionalism } \\
\text { Standard } 1 \text { of the Compass. }\end{array}$ & 9 & 2 & & \\
\hline $\begin{array}{l}\text { 8) A portfolio will be necessary to document Professionalism } \\
\text { Standard } 2 \text { (self-reflection of the teacher) of the Compass. }\end{array}$ & 9 & 2 & & \\
\hline A. Highly effective teaching competency & $\begin{array}{l}\text { B. Effective teaching } \\
\text { competency }\end{array}$ & $\begin{array}{l}\text { C. Not needed as a } \\
\text { teaching competency }\end{array}$ & $\begin{array}{l}\text { D. Ineffective } \\
\text { teaching competency }\end{array}$ & \\
\hline $\begin{array}{l}\text { 9) Time for learning, instructional time not wasted } \\
9\end{array}$ & 2 & & & \\
\hline $\begin{array}{l}\text { 10) Routines } \\
6\end{array}$ & 5 & & & \\
\hline $\begin{array}{l}\text { 11) Teacher to student-positive interaction } \\
10\end{array}$ & 1 & & & \\
\hline $\begin{array}{l}\text { 12) Praise \& Accountability } \\
9\end{array}$ & 2 & & & \\
\hline $\begin{array}{l}\text { 13) Art of crafting lesson } \\
6\end{array}$ & 5 & & & \\
\hline $\begin{array}{l}\text { 14) Science-Pedagogy } \\
5\end{array}$ & 6 & & & \\
\hline $\begin{array}{l}\text { 15) Adapting lessons to engage students } \\
10\end{array}$ & 1 & & & \\
\hline $\begin{array}{l}\text { 16) Enthusiasm } \\
7\end{array}$ & 4 & & & \\
\hline $\begin{array}{l}\text { 17) Clarity—clarity concepts } \\
6\end{array}$ & 4 & & & \\
\hline $\begin{array}{l}\text { 18) Interactions-foster student participation } \\
9\end{array}$ & 2 & & & \\
\hline $\begin{array}{l}\text { 19) Organization of Information } \\
5\end{array}$ & 6 & & & \\
\hline $\begin{array}{l}\text { 20)Effective pacing } \\
7\end{array}$ & 4 & & & \\
\hline $\begin{array}{l}\text { 21) Disclosure of course requirements } \\
4\end{array}$ & 7 & & & \\
\hline $\begin{array}{l}\text { 22) Speech-voice relevancy } \\
1\end{array}$ & 10 & & & \\
\hline $\begin{array}{l}\text { 23) Rapport with students } \\
6\end{array}$ & 5 & & & \\
\hline $\begin{array}{l}\text { 24.) Relevance of information } \\
7\end{array}$ & 4 & & & \\
\hline $\begin{array}{l}\text { 25) Learning centered } \\
8\end{array}$ & 3 & & & \\
\hline $\begin{array}{l}\text { 26) Flexibility } \\
3\end{array}$ & 8 & & & \\
\hline
\end{tabular}




\section{E. BLOCK ET AL.}

\section{Continued}

27) Leadership

3

6

5

29) Skilled in following a model of instruction

5

6

7

30) Skilled in writing instructional objectives

31) Skilled in applying taxonomies of instructional objectives

32) Skilled in describing and analyzing learning tasks

3

33) Skilled in organizing instructional plans 